\title{
AUXILIARY PRINCIPLE TECHNIQUE FOR MULTIVALUED MIXED QUASI-VARIATIONAL INEQUALITIES
}

\author{
MuHAmmad ASLAm NoOR AND THEMISTOCles M. RASSiAS
}

\begin{abstract}
In this paper, we suggest and analyze a class of predictor-corrector methods for solving mixed quasi variational inequalities by using the auxiliary principle technique. We prove that the convergence of these predictor-corrector type methods requires only the partial relaxed strongly monotonicity, which is a weaker condition than co-coercivity. Since the mixed quasi variational inequalities include (quasi) variational inequalities as special cases, our results continue to hold for these problems. Our results represent an improvement and refinement of the previously known results.
\end{abstract}

Mathematics subject classification (2000): 49J40.

Key words and phrases: Variational inequalities, auxiliary principle, iterative methods, convergence.

\section{REFERENCES}

[1] C. BAIOCCHI AND A. CAPElo, Variational and Quasi Variational inequalities, J. Wiley and Sons, New York, 1984.

[2] D. P. Bertsekas and J. Tsitsiklis, Parallel and Distributed Computation: Numerical Methods, Prentice-Hall, Englewood Cliffs, New Jersey, 1989.

[3] J. CranK, Free and Moving Boundary Problems, Clarendon Press, Oxford, U. K. 1984.

[4] F. GiAnNESSI AND A. MAUGERI, Variational Inequalities and Network Equilibrium Problems, Plenum Press, New York, 1995.

[5] F. Giannaessi, A. Maugeri and P. M. Pardalos, Equilibrium Problems: Nonsmooth Optimization and Variational inequality Models, Kluwer Academic Press, Dordrecht, Holland, 2001.

[6] R. Glowinski, J. L. Lions And R. TREMOLIERes, Numerical Analysis for Variational Inequalities, North-Holland, Amsterdam, 1981.

[7] R. Glowinski And Le TAlLEC, Augmented Lagrangian and Operator Splitting Methods in Nonlinear Mechanics, SIAM, Philadelphia, 1989.

[8] N. KIKUCHI AND J. T. ODEN, Contact Problems in Elasticity, SIAM, Philadelphia, 1988.

[9] D. KinderlehreR AND G. STAMPACCHIA, An Introduction to Variational inequalities and Their Applications, SIAM, Philadelphia, 2000.

[10] J. L. Lions and G. Stampacchia, Variational Inequalities, Comm. Pure Appl. Math. 20(1967), 493-512.

[11] Z. Naniewicz and P. D. PANagiotopoulos, Mathematical Theory of Hemivariational inequalities and Applications, Marcel Dekker, New York, 1995.

[12] M. Aslam NoOR, General variational inequalities, Appl. Math. Letters, 1(1988), 119-121.

[13] M. Aslam NoOR, On a class of variational inequalities, J. Math. Anal. Appl. 128(1987), 138-155.

[14] M. Aslam NooR, Nonlinear variational inequalities in elastostatics, Int. J. Eng. Sci. 26(1987), 1043-1053.

[15] M. Aslam Noor, Some recent advances in variational inequalities, Part I, basic concepts, New Zealand J. Math. 26(1997), 53-80.

[16] M. AsLam Noor, Some recent advances in variational inequalities, Part II, other concepts, New Zealand J. Math. 26(1997), 229-255.

[17] M. Aslam Noor, Generalized set-valued variational inequalities, Le Math. 52(1997), 3-24. 
[18] M. Aslam Noor, Set-valued mixed quasi variational inequalities and implicit resolvent equations, Math. Computer Modelling, 29(1999), 1-11.

[19] M. Aslam NoOR, A class of new iterative methods for general mixed variational inequalities, Math. Computer Modelling, 31(2000), 11-19.

[20] M. ASLAM NOOR, Some predictor-corrector methods for multivalued variational inequalities, J. Optim. Theory Appl. 108(2001), 659-670.

[21] M. Aslam NooR, Mixed Quasi variational inequalities, Appl. Math. Computation, 146(2003), 553-579.

[22] M. Aslam NoOR, K. InAYAT NOOR AND TH. M. Rassias, Some aspects of variational inequalities, J. Comput. Appl. Math. 47(1993), 285-312.

[23] G. StAMPACCHIA, Formes bilineaires coercivites sue les ensembles convexes, C. R. Acad. Sci., 258(1964), 4413-4416.

[24] D. L. ZhU AND P. MARCotTE, Cocoercivity and its role in the convergence of iterative schemes for solving variational inequalities, SIAM J. Optim. 6(1996), 714-726. 